\title{
Is alanine aminotransferase flare-up in nucleos(t)ide analogue treatment of chronic hepatitis B a promising, rather than a devastating, sign?
}

\author{
Nae-Yun Heo \\ Department of Internal Medicine, Haeundae Paik Hospital, Inje University College of Medicine, Busan, Korea
}

Keywords: Hepatitis B; Nucleos(t)ide analogue; Alanine aminotransferase

\section{See Article on Page 154}

Hepatitis B is the most common cause of chronic viral hepatitis in the world, and an estimated 257 million people are living with a current hepatitis $B$ virus (HBV) infection, which is defined as being HBsAg positive. In 2015, 887,000 deaths were due to hepatitis $B$, mostly from complications such as cirrhosis and hepatocellular carcinoma. ${ }^{1}$ The initial antiviral therapy for chronic hepatitis B (CHB) was interferon, which functioned as an immune modulator to enhance the host immunity against HBV. However, its clinical efficacy was suboptimal; the rate of virological response defined as HBeAg seroconversion was $15-32 \%{ }^{2,3}$ Since the first oral nucleoside analogue (NUC) for CHB, lamivudine, was approved in 1998, it has shown a rapid virologic suppression, but long-term treatment with lamivudine has induced the development of drugresistant variants. ${ }^{4,5}$ The clinical practice guidelines suggested entecavir (ETV) and tenofovir dipivoxil fumarate (TDF) as the first line oral NUCs because these drugs showed high antiviral efficacy and high genetic barrier for drug resistance. ${ }^{6-8}$ Owing to effective oral
NUCs, the long-term outcome of patients with CHB dramatically improved, and many patients escaped liver-related mortality. ${ }^{9}$

Nevertheless, some patients with CHB showed elevated alanine aminotransferase (ALT) levels during NUC therapy, which made clinicians concerned about aggravation of liver function and failure of antiviral treatment. In the era of interferon therapy, this phenomenon was also observed during the early stage of treatment. Flink et al. presented two types of ALT flares in patients with CHB treated with peg-interferon $\alpha-2 b$, in which ALT flare following a decrease in HBV DNA was associated with high treatment response, compared with ALT flare following an increase in HBV DNA ( $58 \%$ versus $20 \%){ }^{10}$ For lamivudine, acute ALT flare was related to high HBeAg loss or seroconversion. In contrast, late ALT flare during treatment implied the occurrence of drug resistance mutation and biochemical breakthrough following virological breakthrough. $^{5}$

According to a study by Seo et al. ${ }^{11}, 7$ of 181 CHB patients (3\%) showed early ALT flare (>10xULN) without viral breakthrough during administration of TDF, and all of them recovered without decompensation and were able to maintain virological response.

\section{Abbreviations:}

$A L T$, alanine aminotransferase; CHB, chronic hepatitis B; ETV, entecavir; HBV, hepatitis B virus; NUC, nucleos(t)ide analogue; TDF, tenofovir dipivoxil fumarate

\section{Corresponding author : Nae-Yun Heo}

Department of Internal Medicine, Haeundae Paik Hospital, Inje University College of Medicine, 875 Haeun-daero, Haeundae-gu, Busan 48108, Korea Tel: +82-51-797-1340, Fax: +82-51-797-1340.

E-mail: nyheo@hanmail.net

http://orcid.org/0000-0001-6571-8935 
Table 1. Proportion of on-treatment alanine aminotransferase elevation among patients with chronic hepatitis B in major clinical trials dealing with nucleos(t)ide analogues

\begin{tabular}{|c|c|c|}
\hline & $\begin{array}{c}\text { Grade } 3 \text { (ALT >5-10×ULN) } \\
\text { and } 2 \times \text { baseline value }\end{array}$ & $\begin{array}{l}\text { Grade } 4 \text { (ALT } 10 \times \text { ULN) } \\
\text { and } 2 \times \text { baseline value }\end{array}$ \\
\hline \multicolumn{3}{|l|}{ Entecavir } \\
\hline Chang et al. $(2006)^{14^{*}}$ & $37 / 354(10 \%)$ & $12 / 354(3 \%)$ \\
\hline Lai et al. $(2006)^{15 t}$ & $6 / 325(2 \%)$ & $3 / 325(<1 \%)$ \\
\hline \multicolumn{3}{|l|}{ Tenofovir disoproxil fumarate } \\
\hline Marcellin et al. $(2008)^{12 \ddagger}$ & $13 / 426(3 \%)$ & $11 / 426(3 \%)$ \\
\hline Chan et al. $(2016)^{13 \ddagger}$ & $36 / 292(13 \%)^{5}$ & \\
\hline
\end{tabular}

ALT, alanine aminotransferase; ULN, upper limit of the normal range.

*Entacavir $0.5 \mathrm{mg} /$ day for a minimum of 52 weeks in $\mathrm{HBeAg}$-positive $\mathrm{CHB}$; ${ }^{\dagger}$ Entacavir $0.5 \mathrm{mg} /$ day for a minimum of 52 weeks in $\mathrm{HBeAg}$-negative

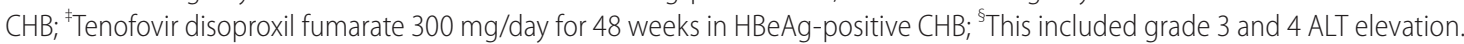

Although TDF is one of the highly potent NUCs that induce rapid reduction of viral load, a few subjects taking TDF showed early ALT flare without transient decompensation. ${ }^{12,13}$ This trend was also similar to cases treated with ETV (Table 1)..$^{14,15}$ Therefore, early ALT flare on NUCs seems to be a good predictor of treatment response in NUC therapy for CHB.

This phenomenon can be explained as an immune reconstitution phenomenon. In HIV/HBV co-infected patients with a normal liver function profile and high HBV viral load, highly active antiretroviral therapy introduced acute hepatitis after the CD4+ T-cell count was recovered. This is representative of immune reconstitution inflammatory syndrome, in which the cytopathic lysis of HBVinfected hepatocyte occurs through recovered immunity from medication. ${ }^{16}$ In HBV-mono infected patients, the high viral load was associated with suppression of the adaptive immune system through CD4+ and CD8+ T-cell mediated reactions. Boni et al. showed that during the early period of lamivudine treatment in HBeAg-positive CHB patients with high a viral load, CD4+ T-cell proliferation was elevated since the commencement of NUC therapy. Two of 12 patients showed ALT elevation during treatment. ${ }^{17}$ This study suggested that restoration of the antiviral immune mechanism by suppression of high viremia on NUCs was associated with host-related cell lysis of HBV-infected hepatocytes.

However, it is prudent to closely monitor the liver function in the early course of NUC therapy in the patients with CHB, especially in the case of decompensated cirrhosis, acute liver failure, or acute on chronic liver failure. In these cases, there is a high risk of mortality by severe necroinflammation by immune reconstitution. Fujiwara et al. showed that steroid therapy was effective during the early period of NUC therapy in severe acute hepatitis $B^{18}$; however, this strategy was not validated in a large patient population.
In conclusion, Seo et al." showed that early ALT flare on highly potent NUC was relatively safe and led to successful virological responses in compensated CHB patients. In addition, to achieve partial immune reconstitution by NUCs, additional immune therapy is expected to completely eliminate HBV in the liver in further investigations.

\section{Conflicts of Interest}

Nae-Yun Heo received lecture fees from Gilead Sciences and Bristol-Myers Squibb.

\section{REFERENCES}

1. World Health Organization. Mediacentre, Fact sheet. <http://www. who.int/mediacentre/factsheets/fs204/en/>. Accessed 2017.06.04.

2. Lok $A S$, Lai $C L$, Wu PC, Leung EK. Long-term follow-up in a randomised controlled trial of recombinant alpha 2-interferon in Chinese patients with chronic hepatitis B infection. Lancet 1988;2:298302.

3. Lau GK, Piratvisuth T, Luo KX, Marcellin P, Thongsawat S, Cooksley $G$, et al. Peginterferon Alfa-2a, lamivudine, and the combination for HBeAg-positive chronic hepatitis B. N Engl J Med 2005;352:26822695.

4. Lai CL, Chien RN, Leung NW, Chang TT, Guan R, Tai DI, et al. A oneyear trial of lamivudine for chronic hepatitis B. Asia Hepatitis Lamivudine Study Group. N Engl J Med 1998;339:61-68.

5. Lok AS, Lai CL, Leung N, Yao GB, Cui ZY, Schiff ER, et al. Long-term safety of lamivudine treatment in patients with chronic hepatitis $B$. Gastroenterology 2003;125:1714-1722.

6. Sarin SK, Kumar M, Lau GK, Abbas Z, Chan HL, Chen CJ, et al. Asian-Pacific clinical practice guidelines on the management of hepatitis B: a 2015 update. Hepatol Int 2016;10:1-98.

7. Terrault NA, Bzowej NH, Chang KM, Hwang JP, Jonas MM, Murad 
$\mathrm{MH}$, et al. AASLD guidelines for treatment of chronic hepatitis $\mathrm{B}$. Hepatology 2016;63:261-283.

8. European Association For The Study Of The Liver. EASL clinical practice guidelines: Management of chronic hepatitis B virus infection. J Hepatol 2012;57:167-185.

9. Lim YS, Han S, Heo NY, Shim JH, Lee HC, Suh DJ. Mortality, liver transplantation, and hepatocellular carcinoma among patients with chronic hepatitis B treated with entecavir vs lamivudine. Gastroenterology 2014;147:152-161.

10. Flink HJ, Sprengers D, Hansen BE, van Zonneveld M, de Man RA, Schalm SW, et al. Flares in chronic hepatitis B patients induced by the host or the virus? Relation to treatment response during Peginterferon \{alpha\}-2b therapy. Gut 2005;54:1604-1609.

11. Seo HY, Lee HA, Ko SY, Wang JH, Kim JH, Choe WH, et al. Clinical impact of the early alanine amininotransferase flare during tenofovir monotherapy in treatment-naïve patients with chronic hepatitis B. Clin Mol Hepatol 2017;23:154-159.

12. Marcellin P, Heathcote EJ, Buti M, Gane E, de Man RA, Krastev Z, et al. Tenofovir disoproxil fumarate versus adefovir dipivoxil for chronic hepatitis B. N Engl J Med 2008;359:2442-2455.

13. Chan HL, Fung S, Seto WK, Chuang WL, Chen CY, Kim HJ, et al.
Tenofovir alafenamide versus tenofovir disoproxil fumarate for the treatment of HBeAg-positive chronic hepatitis B virus infection: a randomised, double-blind, phase 3, non-inferiority trial. Lancet Gastroenterol Hepatol 2016;1:185-195.

14. Chang TT, Gish RG, de Man R, Gadano A, Sollano J, Chao YC, et al. A comparison of entecavir and lamivudine for HBeAg-positive chronic hepatitis B. N Engl J Med 2006;354:1001-1010.

15. Lai CL, Shouval D, Lok AS, Chang TT, Cheinquer H, Goodman Z, et al. Entecavir versus lamivudine for patients with $\mathrm{HBeAg}$-negative chronic hepatitis B. N Engl J Med 2006;354:1011-1020.

16. Ofotokun I, Smithson SE, Lu C, Easley KA, Lennox JL. Liver enzymes elevation and immune reconstitution among treatment-naive HIVinfected patients instituting antiretroviral therapy. Am J Med Sci 2007;334:334-341.

17. Boni C, Bertoletti A, Penna A, Cavalli A, Pilli M, Urbani S, et al. Lamivudine treatment can restore $T$ cell responsiveness in chronic hepatitis B. J Clin Invest 1998;102:968-975

18. Fujiwara K, Yasui S, Okitsu K, Yonemitsu Y, Oda S, Yokosuka O. The requirement for a sufficient period of corticosteroid treatment in combination with nucleoside analogue for severe acute exacerbation of chronic hepatitis B. J Gastroenterol 2010;45:1255-1262. 